\title{
$\mathrm{N}$ 스크린 서비스의 이용행태, 콘텐츠, 기능, 비용이 이용 만족도와 지속이용의사에 미치는 영향에 관한 연구 \\ 김 동 우 $^{a}$, 이 영 주 ${ }^{\text {\# }}$
}

\section{The Impact of User Behavior, Contents, Function, Cost on Use Satisfaction and the Continued Use Intention of the N-screen Service Users}

\author{
Dong-Woo Kim ${ }^{\text {a) }}$ and Yeong-Ju Lee ${ }^{\text {a) }}$
}

요 약

본 연구는 $\mathrm{N}$ 스크린 서비스의 이용 행태(교차이용, 개인별 단말기 보유량, $\mathrm{N}$ 스크린 이용을 위한 지불금액, $\mathrm{N}$ 스크린 이용시간), 콘텐츠 특성(채널의 다양성, $\mathrm{VOD}$ 의 다양성), 기능적 요인(시스템품질, 인터페이스, 결제시스템), 비용에 대한 이용자의 인식이 이용만 족도와 지속이용의사에 미치는 영향을 살펴보았다. $\mathrm{N}$ 스크린 유료 경험이 있는 이용자를 대상으로 $(\mathrm{N}=498)$, 웹을 통한 설문조사를 한 결과, 이용만족도에 가장 큰 영향을 미치는 요인은 기능적 요인 중 인터페이스로 나타났으며, 결제시스템, $\mathrm{VOD}$ 의 다양성, 채널의 다 양성, 비용 순으로 유의한 변인인 것으로 나타났다. 본 연구는 이용자 차원에서 $\mathrm{N}$ 스크린 서비스 만족에 영향을 주는 요인들을 밝혀 냄으로써, 스마트 미디어 환경에서 OTT 서비스 활성화를 위한 기초 자료를 제공하는 데 의의가 있다.

\section{Abstract}

This study aims to find out the influences of user behavior, content characteristics, functional factors and user's perception in cost on user satisfaction and continuous intention in N-Screen service. Web survey was conducted for 498 users who have used $\mathrm{N}$ screen service. The results show that the most influential factor contributing to user satisfaction is user interface. VOD diversity, payment system, cost, channel diversity are also meaningful factors. Identifying the critical factors which impact on user satisfaction, this study can provide the basic data for activating OTT service in smart media environment.

Keyword : N Screen, user satisfaction, continued use intention, contents diversity, service quality

a) 서울과학기술대학교 IT정책전문대학원(Seoul National University of Science and Technology, Graduate School of Public Policy and Information Technology)

‡ Corresponding Author : 이영주(Yeong-Ju Lee) E-mail: liberty@seoultech.ac.kr Tel: $+82-2-390-4525$

Manuscript received 2, August 2013 Revised 26, Septemper 2013 Accepted 26, Septemper 2013

\section{I. 서 론}

스마트 미디어 환경이 되면서 방송 콘텐츠 유통사업자들 은 개방형 인터넷과 $\mathrm{N}$ 스크린(N-Screen) 기반의 유통 플랫 폼을 확장해가고 있다. $\mathrm{N}$ 스크린이라 함은 여러 개(n)의 스 크린을 통해 언제 어디서나 콘텐츠를 공유하고 실행할 수 
있고 ${ }^{[1]}, \mathrm{TV}, \mathrm{PC}$, 태블릿(Tablet), 스마트폰 등 다양한 디바 이스에서 콘텐츠를 꼻김 없이 이용 가능한 서비스를 말한 다마. 스마트 기기 보급의 확산으로 $\mathrm{PC}$ 이외의 다양한 디바 이스에서 인터넷 접속이 가능해지면서 $\mathrm{N}$ 스크린 유통 플랫 폼이 발전하게 되었는데, 초기 $\mathrm{N}$ 스크린 서비스는 음악, 영 화, 사진, 문서 등의 디지털 콘텐츠를 복수의 단말기에서 동기화하거나 공유하는 스크린 확장의 형태로 시작하였다. 최근의 $\mathrm{N}$ 스크린 서비스는 본격적인 세컨드 스크린으로서 풍부한 이용 데이터를 바탕으로 스마트폰이나 태블릿과 같 은 2 차 단말기를 이용하여 방송 콘텐츠 관련 내용을 검색하 거나 소셜 미디어(Social media)로 공유하거나 이종 서비스 와 제휴하는 다양한 형태로 서비스 플랫폼을 확장하고 있 다.

그동안 국내 미디어 시장에서 $\mathrm{N}$ 스크린 성장이 두드러지 지 않은 것은 국내 유료 방송 시장이 저가로 고착되어 이용 자들의 방송 콘텐츠에 대한 지불의사가 낮은데다가 방송 콘텐츠를 무료로 이용할 수 있는 다양한 경로가 발달되어 있어 유료 가입자 확보가 쉽지 않기 때문이다 ${ }^{[3]}$. 그러나 스 마트 기기 사용이 급속히 증가하면서 이동성, 통합성, 그리 고 다양한 양방향 서비스의 장점을 이용자가 적극적으로 수용할 가능성이 크다. 향후 스마트 TV의 도입으로 가정 내의 고정 TV가 인터넷이 연결되는 시대가 본격적으로 열 린다면 $\mathrm{N}$ 스크린이 동영상 콘텐츠가 유통되는 핵심 서비스 가 될 가능성이 크다마.

그동안 $\mathrm{N}$ 스크린에 대한 연구는 $\mathrm{N}$ 스크린과 홈 $\mathrm{TV}$ 간 대체 여부에 관계에 대한 연구 ${ }^{[5]}, \mathrm{N}$ 스크린 서비스의 잠재 적 수용의도에 관한 연구 ${ }^{[1]}, \mathrm{N}$ 스크린 서비스 구매 의도 ${ }^{[2]}$ 에 영향을 미치는 연구 등 $\mathrm{N}$ 스크린 서비스가 시작되던 초 기에 $\mathrm{N}$ 스크린을 이용하지 않는 잠재적 수용자를 대상으로 이루어진 탐색적 연구의 특성이 강했다. 본 연구는 $\mathrm{N}$ 스크 린 서비스를 이용자를 대상으로 교차이용과 같은 이용자의 이용행태와 채널 및 VOD 다양성과 같은 콘텐츠 요인 그리 고 인터페이스와 시스템품질, 결제시스템과 같은 기능적 요인, 비용 등의 요인이 $\mathrm{N}$ 스크린 이용만족도에 어떤 영향 을 미치며, 이용만족도와 지속이용의도간의 관계는 어떠한 지 알아보고자 한다. $\mathrm{N}$ 스크린 서비스가 유료 서비스로 자 리잡아 가는 상황에서 향후 $\mathrm{N}$ 스크린 서비스 이용을 보다
활성화시키기 위한 이용 충족 요인을 추가로 밝혀냄으로써 기존 연구 결과를 확장할 수 있을 것으로 기대한다. 또한, 실용적 차원에서 이용경험을 토대로 향후 스마트TV를 활 성화시킬 수 있는 서비스, 기술 및 전략에 필요한 자료를 제시해 줄 수 있을 것으로 판단된다.

\section{II. 선행연구 검토}

\section{N 스크린 서비스 만족도에 영향을 주는 요인}

$\mathrm{N}$ 스크린 환경은 전통적인 미디어 콘텐츠의 이용맥락인 시간, 공간, 콘텐츠간의 동시성을 해체하며 새로운 이용 맥 락을 제시하고 있으며, $\mathrm{N}$ 스크린 서비스가 제공하는 인터 페이스는 기존과 다른 이용경험을 창출하고 있다. 또한, $\mathrm{N}$ 스크린 환경은 콘텐츠 소비를 위해 특정 단말기를 이용해 야 했던 콘텐츠 비즈니스의 근본적 변화를 가져오고 있다. 스마트 모바일 단말기의 보급이 확산되면서 멀티 디바이스 를 통해 $\mathrm{N}$ 스크린을 제공하고 고객의 니즈(Needs)에 맞게 새로운 서비스들과의 제휴를 확장해 가고 있다는 것이다. 황주성(2012)은 스마트 디바이스 환경에서 이용자들이 디 바이스를 연결하여 연속적으로 이용하는 행태에 주목하여 단말기간 연계이용(Multi-device use)라는 개념을 제시하고 있다. 연계이용은 디바이스 이용의 시·공간 연계성과 디바 이스 이용의 시스템적 연계성에 따라 동시이용, 교차이용, 연결이용 세 가지로 구분되며, 디바이스 간 연계이용의 유 형은 표 1 과 같다.

표 1. 디바이스 간 연계이용의 유형 구분[6]

Table 1. Classification of multi-device use[6]

\begin{tabular}{|c|c|c|c|}
\hline \multicolumn{2}{|c|}{} & \multicolumn{2}{c|}{ Connection } \\
\cline { 2 - 4 } & $\begin{array}{c}\text { non-systemetic } \\
\text { connection }\end{array}$ & $\begin{array}{c}\text { systemetic } \\
\text { connection }\end{array}$ \\
\hline \hline \multirow{2}{*}{$\begin{array}{c}\text { Time \& } \\
\text { Space }\end{array}$} & $\begin{array}{c}\text { non-connection in } \\
\text { time \& space }\end{array}$ & individual use & cross-use \\
\cline { 2 - 4 } & $\begin{array}{c}\text { connection in } \\
\text { time \& space }\end{array}$ & $\begin{array}{c}\text { simultaneous } \\
\text { use }\end{array}$ & $\begin{array}{c}\text { continuous } \\
\text { use }\end{array}$ \\
\hline
\end{tabular}


이 중 교차이용은 동일한 서비스를 두 개 이상의 단말기 에서 연속적으로 이용하는 행위를 말하며맘, 시·공간적으로 연계되지 않지만 시스템적으로 연계되는 것으로 이동 중에 스마트폰을 통해 $\mathrm{VOD}$ 를 감상하다가 집에서 $\mathrm{PC}$ 로 이어보 는 행위 혹은 태블릿으로 다시 회사에서 보는 행위 등 두 개 이상의 단말기에서 연속적으로 하는 행위로 설명될 수 있다.

한편, $\mathrm{N}$ 스크린은 방송콘텐츠를 제공하는 서비스이기 때 문에 이용만족도에 영향을 주는 요인으로 콘텐츠 특성을 살펴볼 필요가 있다. $\mathrm{N}$ 스크린은 기존의 $\mathrm{TV}$ 에서 제공하는 거의 모든 실시간 채널을 제공하고 있고 더불어 디지털 케 이블이나 IPTV, 웹상에서만 제공했던 VOD 서비스도 제공 하는 등 이용자가 다양한 콘텐츠를 쉽게 접근할 수 있는 환경을 갖추고 있다. 김수현(2008)는 뉴미디어 환경이 시작 된 이후 콘텐츠의 중요성이 커지고 있음을 강조하며 IPTV 의 경우에도 콘텐츠 다양성이 유용성과 용이성에 정적인 영향을 주는 것으로 밝히고 있다 ${ }^{[7]}$. 뿐만 아니라 UCC(User Created Contents)와 같은 인터넷 기반의 짧은 영상에 관한 연구에서도 콘텐츠 다양성은 주요한 요인들로 도출되고 있 다 ${ }^{[8]}$.

또한, 기능적인 측면에서 $\mathrm{N}$ 스크린 서비스는 폐쇄망을 사용하는 유료방송과는 달리 오픈망을 사용하기 때문에 사업자가 일정한 시스템 품질을 보장할 의무가 없다. 그럼 에도 불구하고 $\mathrm{N}$ 스크린은 어떠한 플랫폼과 디바이스에서 도 언제, 어디서나 제공될 수 있도록 유무선 네트워크와 운 영체제를 통합하여 편리하고 만족스러운 이용자 경험(UX) 을 제공해야 한다 ${ }^{[9]}$. 복잡하고 다양한 콘텐츠를 이용함에 있어 쉽고 편리한 인터페이스에 대한 이용자들의 욕구는 더욱 더 커지고 있다. 스마트TV의 채택에 관한 연구에서는 감성적 인터페이스와 기능적 인터페이스 모두 채택의도에 정적인 영향을 주고 있으며, 기능적 인터페이스는 콘텐츠 의 효과적인 시각적, 유용, 조작 등과 매우 밀접한 관계가 있음이 밝혀졌다 ${ }^{[10]}$. 한편, $\mathrm{N}$ 스크린 서비스는 다양한 $\mathrm{OS}$ 와 웹 환경에서 결제가 가능하도록 지원하고 있다. 특히 스마 트폰이 국민들의 일상생활에 필수품으로 자리잡으면서 스 마트폰의 소액 결제 시스템의 이용이 증가하고 있으며, 편 리한 결제 시스템은 고객 만족도에 영향을 미치는 것으로
나타나고 있다 ${ }^{[11]}$.

$\mathrm{N}$ 스크린 요금제는 크게 정액제 상품과 단건 상품으로 나눌 수 있다. 정액제 상품은 월(30일) 단위로 제한된 범위 안에 콘텐츠를 이용하는 것으로 실시간 채널 이용과 다시 보기(VOD) 상품 으로 구분되고, 서비스 유형에 따라 요금 이 상이하다. 실제 $\mathrm{N}$ 스크린의 유료 서비스나 구매의도 차 원에서 다양한 접근들이 계속되고 있는데, $\mathrm{N}$ 스크린의 인 지된 비용과 비용 부담감은 이용 의도에 영향을 미치는 것 으로 나타나고 있다 ${ }^{[2]}$. 하지만 이 연구들에서 제시한 비용 은 절대적인 금액으로 제시되기보다는 이용자가 주관적으 로 인지하는 비용에 대한 합리성 또는 민감성의 정도를 의 미하므로 연구 결과의 해석에 주의를 필요로 한다.

표 2. N 스크린 서비스 만족도에 영향을 주는 요인

Table 2. Factors which have impact on satisfaction of $\mathrm{N}$ screen service

\begin{tabular}{|c|c|c|}
\hline concept & research & reference \\
\hline use behavior & $\begin{array}{l}\text { proposed the concept of } \\
\text { multi-device use(individual use, } \\
\text { cross-use, simultaneous use) in } \\
\text { smart devices environment }\end{array}$ & [6] \\
\hline \multirow[t]{2}{*}{ contents } & $\begin{array}{l}\text { IPTV contents diversity affects } \\
\text { the usability and usefulness. } \\
\text { Ease of use and usefulness } \\
\text { affect the satisfaction of service }\end{array}$ & [7] \\
\hline & $\begin{array}{l}\text { VOD contents diversity affects } \\
\text { satisfaction }\end{array}$ & [8] \\
\hline \multirow{3}{*}{ function } & $\begin{array}{l}\text { System quality of } \mathrm{N} \text {-screen } \\
\text { service affects satisfaction }\end{array}$ & [9] \\
\hline & $\begin{array}{l}\text { Interface of Smart TV affects } \\
\text { satisfaction }\end{array}$ & [10] \\
\hline & $\begin{array}{l}\text { smartphone payment system } \\
\text { affects satisfaction }\end{array}$ & [11] \\
\hline cost & $\begin{array}{l}\text { Perceived cost of } n \text {-screen } \\
\text { service affects satisfaction }\end{array}$ & [2] \\
\hline
\end{tabular}

\section{N 스크린에 대한 이용 만족도와 지속사용의사의 관계}

일반적으로 만족은 특정 대상이나 상황에 대한 욕구 충 족 또는 기대달성 등의 주관적인 감정적 반응을 하며 경험 을 통해 충족된 정도에 따라 드러나는 전반적인 감정 상태 로 볼 수 있다 ${ }^{[12]}$. 이용자의 해당 매체에 대한 지속적인 사 용은 만족정도에 의해 결정된다는 사실은 다수의 선행연구 
를 통해 확인된 바 있다미. IPTV 시청에 대한 만족도가 높 을 때 지속이용의도에 정적인 영향을 미치며 ${ }^{[13]}$, 온라인 채 널의 전반적인 만족은 소비자가 해당 채널을 다시 이용하 게 만드는 효과가 있다 ${ }^{[14]}$. 정철호.정덕화(2009)는 UCC 콘 텐츠 품질이 사용자 만족도와 지속이용의도에 미치는 영향 을 연구하였는데, UCC 콘텐츠 품질 중 완전성, 다양성, 유 희성, 적시성 등의 4 가지 요인이 사용자 만족과 지속이용의 도에 긍정적인 영향을 보이며, 만족도와 지속이용의도 간 에도 긍정적인 영향이 있음이 밝혀졌다 ${ }^{[8]}$. 한편, $\mathrm{N}$ 스크린 에 대해 만족하지 않을 경우 지속사용의사에 부정적 예측 력을 지니고 있으며, 특히 여러 요인 가운데 콘텐츠에 대한 불만이 높을 때 지속사용의사에 부정적인 것으로 나타났다 [15].

\section{III. 연구문제 및 연구방법}

\section{1. 연구문제}

본 연구는 선행연구를 바탕으로 $\mathrm{N}$ 스크린의 이용만족도
에 영향을 주는 변인을 $\mathrm{N}$ 스크린의 이용행태(교차이용, 단 말기 보유량, 서비스 지불금액, $\mathrm{N}$ 스크린 이용시간), 콘텐 츠(채널의 다양성, $\mathrm{VOD}$ 의 다양성), 기능(시스템 품질, 인 터페이스, 결제시스템), 비용 등으로 도출하였다. 그리고 $\mathrm{N}$ 스크린에 대한 이용 만족도가 지속이용의사에 어떠한 영 향을 미치는지 알아보고자 그림 1 과 같은 연구모형을 설정 하였다.

연구문제 1. N 스크린 서비스의 이용행태, 콘텐츠, 기능, 비용 요인은 이용 만족도에 어떠한 영향을 미치는가?

연구문제 2. N 스크린 서비스에 대한 이용 만족도는 지속 이용의사에 어떠한 영향을 미치는가?

\section{2. 연구방법}

본 연구에서는 $\mathrm{N}$ 스크린 유료 이용 경험이 있는 응답자 498명을 대상으로 웹사이트에 설문 내역을 구축하여 만든 웹서베이를 실시하였다. 본 조사는 전국 권역의 설문 패널 을 보유한 전문 조사 기관에 의뢰하여 2013년 4월 22일(월)

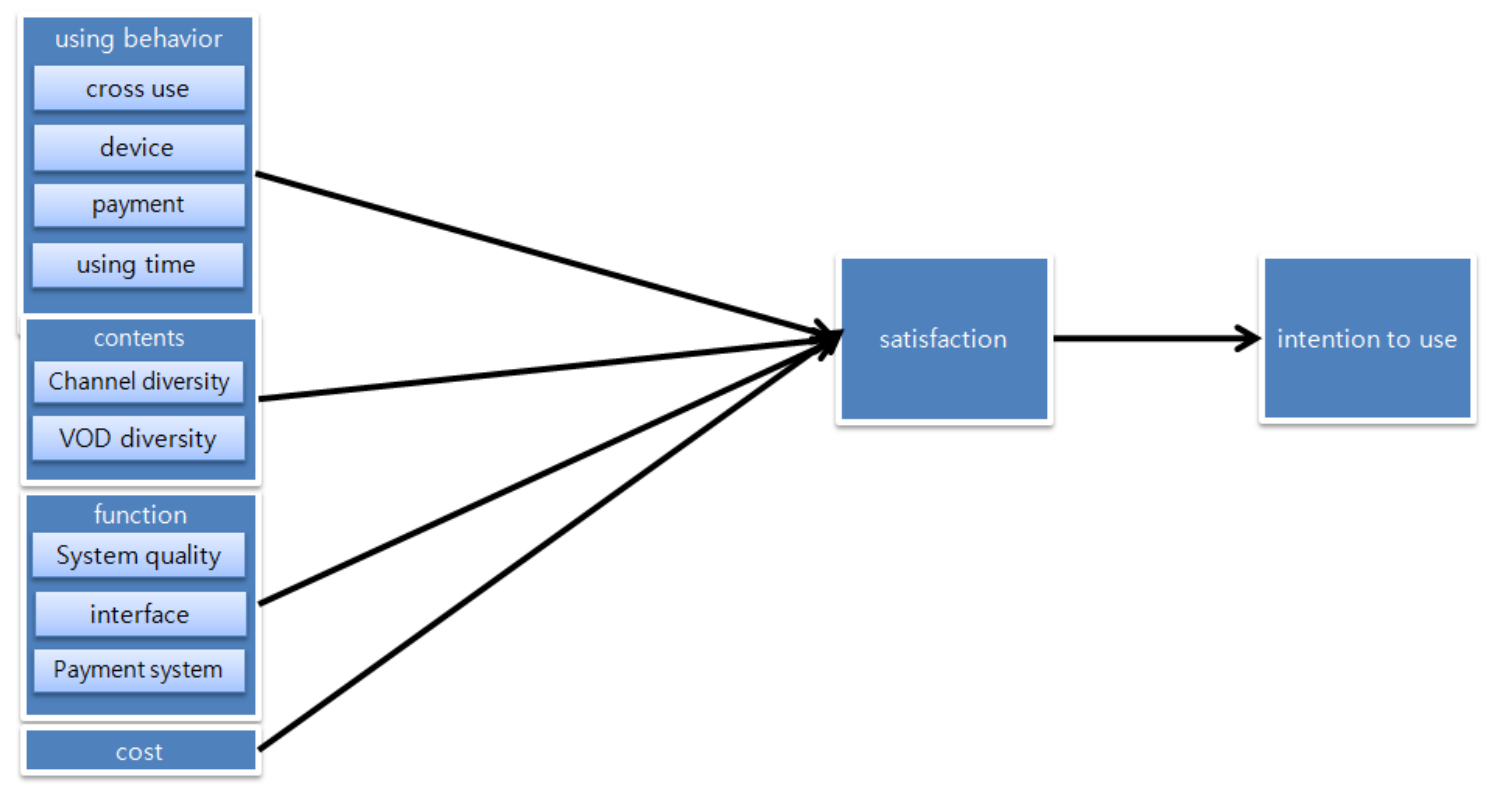

그림 1. 연구모형

Fig. 1. Research model 
부터 29일(월)까지 1주일간 진행하였으며, 조사대상자는 만 19세 이상의 $\mathrm{N}$ 스크린 이용경험이 있는 성인 중 '19 29 세', ‘30 39세', ‘40 49세'의 세 집단을 할당 표집 하였다. 응답자의 인구통계학적 특징은 <표 1>과 같으며, 수집된 자료의 통계적 처리를 위해서 SPSS 19 버전을 활용하였다. 단말기 보유량은 '개인별 스마트폰, 태블릿 노트북, 데스 크탑, 스마트TV 보유정도’로 정의하고 2대부터 5대로 재코 딩하였다. 단말기 보유량은 4개의 디바이스를 보유하고 있 는 사람이 $33.5 \%(\mathrm{~N}=167)$ 로 가장 많았으며, 3 개가 $29.7 \%(\mathrm{~N}=148), 5$ 개가 $20.9 \%(104), 2$ 개가 $15.9 \%(\mathrm{~N}=79)$ 순 으로 단말기를 보유하고 있었다. $\mathrm{N}$ 스크린 서비스를 위한 지불금액은 ' 2 천원 미만', ‘2천원 이상 5 천원미만', '5천원

표 3. 응답자의 인구통계학적 특성 $(\mathrm{N}=498)$

Table 3. Demographic characteristics of the respondents $(N=498)$

\begin{tabular}{|c|c|c|c|}
\hline \multicolumn{2}{|c|}{ classification } & frequency & percentage \\
\hline \multirow{2}{*}{ sex } & male & 255 & 51.2 \\
\hline & female & 243 & 48.8 \\
\hline \multirow{3}{*}{ age } & 19 29 & 169 & 33.9 \\
\hline & 30 39 & 168 & 33.7 \\
\hline & $40 \sim 49$ & 161 & 32.3 \\
\hline \multirow{5}{*}{ education } & high school graduated & 68 & 13.7 \\
\hline & college student & 61 & 12.2 \\
\hline & college graduated & 315 & 63.3 \\
\hline & graduate school student & 14 & 2.8 \\
\hline & $\begin{array}{l}\text { graduate school } \\
\text { graduated }\end{array}$ & 40 & 8.0 \\
\hline \multirow{6}{*}{ income/month } & $\sim 1$ mill. won & 44 & 8.8 \\
\hline & 1 mill. $\sim 2$ mill & 88 & 17.7 \\
\hline & 2 mill. $\sim 3$ mill & 115 & 23.1 \\
\hline & 3 mill. $\sim 4$ mill. & 99 & 19.9 \\
\hline & 4 mill $\sim 5$ mill & 67 & 13.5 \\
\hline & 5 mill & 85 & 17.1 \\
\hline \multirow{4}{*}{ device } & $2 \mathrm{pcs}$ & 79 & 15.9 \\
\hline & $3 \mathrm{pcs}$ & 148 & 29.7 \\
\hline & $4 \mathrm{pcs}$ & 167 & 33.5 \\
\hline & $5 \mathrm{pcs}$ & 104 & 20.9 \\
\hline \multirow{4}{*}{$\begin{array}{l}\text { payment for } \mathrm{N} \\
\text { screen }\end{array}$} & $\sim 2,000$ won & 83 & 16.7 \\
\hline & $2,000 \sim 5,000$ & 210 & 42.2 \\
\hline & $5,000 \sim 10,000$ & 145 & 29.1 \\
\hline & $10,000 \sim 15,000$ & 60 & 12 \\
\hline \multirow{6}{*}{$\begin{array}{l}\mathrm{N} \text { screen } \\
\text { using time }\end{array}$} & $\sim 30 \mathrm{~min}$. & 29 & 5.8 \\
\hline & $30 \min \sim 60 \min$ & 63 & 12.7 \\
\hline & $60 \min \sim 90 \mathrm{~min}$ & 157 & 31.5 \\
\hline & $90 \min \sim 120 \mathrm{~min}$ & 88 & 17.7 \\
\hline & $120 \mathrm{~min} \sim 150 \mathrm{~min}$ & 82 & 16.5 \\
\hline & $150 \min \sim$ & 79 & 15.9 \\
\hline
\end{tabular}

이상 1만원 미만', ‘1만원 이상 1만 5천원 미만'으로 구분하였다. $\mathrm{N}$ 스크린 지불금액은 ' 2 천원 이상 5천원 미 만'의 사용자가 $42.2 \%(\mathrm{~N}=210)$ 로 가장 높게 나타났으며, '5 천원 이상 1만원 미만'이 $29.1 \%(\mathrm{~N}=145)$ 로 다음을 차지 하였다. 하루 평균 $\mathrm{N}$ 스크린 서비스 이용시간은 평균값 95.7 분을 기준으로 ' 30 분 미만' ‘30 60분', ‘60 90분', ‘90 분 120 분', ‘ 120 분 150 분', ‘ 150 분 이상'으로 나누어 재분 류 하였다. $\mathrm{N}$ 스크린 이용시간은 $60 \sim 90$ 분이 $31.5 \%$ $(\mathrm{N}=157)$ 로 가장 높은 비중을 차지했고, 다음으로 90 120 분이 $17.7 \%(\mathrm{~N}=88), 120 \sim 150$ 분이 $16.5 \%(\mathrm{~N}=82), 150$ 분이 상이 $15.9 \%(\mathrm{~N}=79), 30 \sim 60$ 분 $12.7 \%(\mathrm{~N}=63), 30$ 분미만이 $5.8 \%(\mathrm{~N}=29)$ 순으로 나타났다. 이외에 요인들에 대한 조작 적 정의와 설문내용은 <표 $3>$ 와 같으며, 모든 측정 항목들 에 대한 신뢰도(reliability) 지수가 0.7 이상으로 모든 측정 항목들은 바람직한 것으로 볼 수 있다.

\section{IV. 연구결과}

먼저 $\mathrm{N}$ 스크린 이용행태, 콘텐츠 요인, 기능적 요인, 비용 요인이 서비스 만족도에 미치는 영향을 규명하기 위해 독립 변인군이 종속 변인에 미치는 상대적 효과를 평가할 수 있는 계층적 다중 회귀분석(Hierarchical multiple regression analysis)을 시행하였다. 이용자의 인구통계학적 요인은 유 의미하지 않은 결과를 나타내는 관계로 모델에서 제외하였 으며, 1 단계에서는 교차이용, 단말기 보유량, 서비스 지불금 액, 이용시간을 포함한 이용행태 요인으로 분석하였으며, 2단계에서 콘텐츠 요인(채널의 다양성, $\mathrm{VOD}$ 의 다양성)들을 추가하였고, 3 단계에서는 기능적 요인(시스템품질, 인터페 이스, 결제시스템), 4단계에서는 비용 요인들을 독립변인으 로 추가하여 분석하였다(모델4). 분석결과, 최종 연구모델에 대한 설명력( $\left.\mathrm{Adj} \quad R^{2}\right)$ 은 $.556\left(\mathrm{~F}=42.532^{* *}\right)$ 로 나타났다.

연구결과는 표3과 같으며, 이용 만족도에 가장 큰 영향을 미치는 요인은 기능적 요인 중 인터페이스와 결제시스템으 로 나타났다. 그리고 $\mathrm{VOD}$ 다양성, 채널 다양성과 같은 콘 텐츠 요인도 통계적으로 유의미하게 나타났다. 그러나 교 차이용정도, 단말기 보유량, 지불금액, 이용시간과 같은 이 
용 행태와 관련된 요인은 유의미하게 나타나지 않았다.

연구문제 2 의 $\mathrm{N}$ 스크린 이용만족도가 지속이용의사에 미치는 영향을 알아보기 위해 독립변인으로 이용만족도를, 지속이용의사를 종속변인으로 설정하고 회귀 분석을 실시 하였다. 그 결과 Beta 값은 $.763\left(\mathrm{t}=26.263^{* *}\right)$ 로 유의미하게 나타냈다.
$\mathrm{N}$ 스크린 서비스가 시작되면서 단순한 콘텐츠 소비방식 에 머무르지 않고 복합적이고 다층적인 이용경험과 이용맥 락을 창출하고 있다 ${ }^{[2]}$. 본 연구는 콘텐츠, 기능, 비용이 이용 만족도에 영향을 미치는 요인과 더불어 이용자의 이용행태 에 집중하여 이용경험과 맥락차원에서 이용 충족을 결정하 는 요인을 밝히고자 하였다.

표 4. 주요 변인의 신뢰도

Table 4 . The reliability of the main variables

\begin{tabular}{|c|c|c|c|c|c|}
\hline \multicolumn{2}{|l|}{ 구 분 } & operational definition & statement & reliability & mean \\
\hline \multirow{4}{*}{ using behavior[6] } & cross use & $\begin{array}{c}\text { use behavior of using } \\
\text { continuously } \mathrm{N} \text { screen } \\
\text { service with more than two } \\
\text { devices }\end{array}$ & $\begin{array}{l}\text { I tend to use VOD with more than two devices such as } \\
\text { smartphone, tablet, PC when viewing } \mathrm{N} \text { screen service } \\
\text { I tend to watch contents in advance or watch contents } \\
\text { continuously with more than two devices such } \\
\text { smartphone, tablet, PC when viewing } \mathrm{N} \text { screen service }\end{array}$ & .888 & 4.109 \\
\hline & device & how many device user has & $\begin{array}{l}\text { how many device user has among smartphone, tablet, } \\
\text { desktop, smart TV }\end{array}$ & - & - \\
\hline & payment & $\begin{array}{l}\text { payment per month for using } \\
\mathrm{N} \text { screen service }\end{array}$ & ' 2,000', '2000 5000', ‘5000 10,00’, '10,000 15,000’ & - & - \\
\hline & using time & $\begin{array}{l}\mathrm{N} \text { screen using time per a } \\
\text { day }\end{array}$ & $\begin{array}{l}\text { average using time for pooq, tving, olletvnow, Btv, } \\
\text { hoppin, Utv }\end{array}$ & - & - \\
\hline \multirow[b]{2}{*}{ contents[7][8] } & $\begin{array}{l}\text { channel } \\
\text { diversity }\end{array}$ & $\begin{array}{l}\text { how many user can use } \\
\text { Live(linear) channel }\end{array}$ & $\begin{array}{l}\text { there is enough live(linear) channel in the } \mathrm{N} \text { screen } \\
\text { service I use } \\
\text { I can use most of live channel I want }\end{array}$ & .790 & 4.498 \\
\hline & $\begin{array}{l}\text { VOD } \\
\text { diversity }\end{array}$ & $\begin{array}{l}\text { how many user can use } \\
\text { non-linear (VOD) contents }\end{array}$ & $\begin{array}{l}\text { there is enough VOD contents in the } \mathrm{N} \text { screen service } \\
\text { I use } \\
\text { I can use most of VOD contents I want } \\
\text { there is enough recent VOD contents in the } \mathrm{N} \text { screen } \\
\text { servce I use }\end{array}$ & .844 & 4.731 \\
\hline \multirow{3}{*}{ function[9][10][11] } & $\begin{array}{l}\text { system } \\
\text { quality }\end{array}$ & $\begin{array}{l}\text { supply contents stably and } \\
\text { ceaselessly via } \\
\text { wired/wireless network }\end{array}$ & $\begin{array}{l}\mathrm{N} \text { screen service is supplied whenever and wherever } \\
\text { seamlessly. } \\
\mathrm{N} \text { screen service is always supplied stably. } \\
\mathrm{N} \text { screen service has reliable system. }\end{array}$ & .896 & 4.511 \\
\hline & interface & $\begin{array}{l}\text { useful, efficient, and easy } \\
\text { manipulation when viewing } \\
\text { contents }\end{array}$ & $\begin{array}{l}\mathrm{N} \text { screen is equipped with usefulness to watch the } \\
\text { contents. } \\
\mathrm{N} \text { screen can be used quickly and easily. } \\
\text { I can select and find menu easily when using } \mathrm{N} \text { screen }\end{array}$ & .831 & 4.659 \\
\hline & $\begin{array}{l}\text { payment } \\
\text { system }\end{array}$ & $\begin{array}{c}\text { perception for payment } \\
\text { system via smartphone and } \\
\text { PC }\end{array}$ & $\begin{array}{l}\text { I am satisfied with payment system of smartphone. } \\
\text { I am satisfied with payment system of PC. }\end{array}$ & .819 & 4.659 \\
\hline \multicolumn{2}{|l|}{$\begin{array}{c}\text { cost } \\
{[2]}\end{array}$} & $\begin{array}{l}\text { perception on the cost } \\
\text { paying for } \mathrm{N} \text { screen service }\end{array}$ & $\begin{array}{l}\text { I think that the } \mathrm{N} \text { screen service monthly fee of } \\
\text { real-time services is cheap. } \\
\text { I think that the } \mathrm{N} \text { screen service monthly fee of VOD } \\
\text { services is cheap. } \\
\mathrm{I} \text { think that } \mathrm{N} \text { screen service Lump sum fee is cheap. }\end{array}$ & .902 & 4.018 \\
\hline \multicolumn{2}{|c|}{$\begin{array}{l}\text { satisfaction } \\
\text { [12][13] }\end{array}$} & $\begin{array}{l}\text { overall satisfaction for } \mathrm{N} \\
\text { screen service }\end{array}$ & $\begin{array}{l}\mathrm{N} \text { screen service is well-suited to my feelings and } \\
\text { emotions. } \\
\text { I think } \mathrm{N} \text { screen useful to me }\end{array}$ & .780 & 4.594 \\
\hline \multicolumn{2}{|c|}{$\begin{array}{l}\text { intention to use } \\
\text { [9][15] }\end{array}$} & $\begin{array}{l}\text { intention to use } \mathrm{N} \text { screen } \\
\text { service continuously }\end{array}$ & $\begin{array}{l}\text { I will continue to use } \mathrm{N} \text { screen service. } \\
\text { I will recommend } \mathrm{N} \text { screen service to others. }\end{array}$ & .857 & 4.588 \\
\hline
\end{tabular}


표 5. N 스크린의 이용행태, 콘텐츠, 기능, 비용이 이용만족도에 미치는 영향 $(\mathrm{N}=498)$

Table 5. The Impact of user behavior, contents, functionality, cost on the used Satisfaction $(\mathrm{N}=498)$

\begin{tabular}{|c|c|c|c|c|}
\hline \multirow{2}{*}{ 구분 } & model 1 & model 2 & model 3 & model 4 \\
\hline & Beta (t) & Beta $(t)$ & Beta (t) & Beta $(t)$ \\
\hline \multicolumn{5}{|l|}{$\begin{array}{c}\text { use } \\
\text { behavior }\end{array}$} \\
\hline $\begin{array}{l}\text { cross } \\
\text { use }\end{array}$ & $\begin{array}{c}.342 \\
\left(8.022^{* *}\right)\end{array}$ & $\begin{array}{c}.129 \\
\left(3.334^{*}\right)\end{array}$ & $\begin{array}{c}.074 \\
\left(2.168^{*}\right) \\
\end{array}$ & $\begin{array}{c}.052 \\
(1.482) \\
\end{array}$ \\
\hline device & $\begin{array}{c}.062 \\
(1.359)\end{array}$ & $\begin{array}{l}.021 \\
(.538)\end{array}$ & $\begin{array}{c}.012 \\
(.377)\end{array}$ & $\begin{array}{l}.013 \\
(.383)\end{array}$ \\
\hline payment & $\begin{array}{c}.063 \\
(1.451) \\
\end{array}$ & $\begin{array}{c}061 \\
(1.677) \\
\end{array}$ & $\begin{array}{c}.050 \\
(1.595)\end{array}$ & $\begin{array}{c}.048 \\
(1.520)\end{array}$ \\
\hline $\begin{array}{l}\text { using } \\
\text { time }\end{array}$ & $\begin{array}{c}-.016 \\
(-.370)\end{array}$ & $\begin{array}{l}-.035 \\
(-.982) \\
\end{array}$ & $\begin{array}{c}.010 \\
(.305) \\
\end{array}$ & $\begin{array}{c}.002 \\
(.067) \\
\end{array}$ \\
\hline \multicolumn{5}{|l|}{ contents } \\
\hline $\begin{array}{l}\text { channel } \\
\text { diversity }\end{array}$ & & $\begin{array}{c}.252 \\
\left(5.992^{* *}\right)\end{array}$ & $\begin{array}{c}.100 \\
\left(2.594^{*}\right)\end{array}$ & $\begin{array}{c}.099 \\
\left(2.584^{*}\right) \\
\end{array}$ \\
\hline $\begin{array}{c}\text { VOD } \\
\text { diversity }\end{array}$ & & $\begin{array}{c}.387 \\
\left(9.254^{* *}\right)\end{array}$ & $\begin{array}{c}.113 \\
\left(2.676^{*}\right)\end{array}$ & $\begin{array}{c}.123 \\
\left(2.893^{*}\right)\end{array}$ \\
\hline \multicolumn{5}{|l|}{ function } \\
\hline $\begin{array}{l}\text { system } \\
\text { quality }\end{array}$ & & & $\begin{array}{l}-.008 \\
(-.174) \\
\end{array}$ & $\begin{array}{c}-.028 \\
(-.581) \\
\end{array}$ \\
\hline interface & & & $\begin{array}{c}.383 \\
\left(7.158^{* *}\right)\end{array}$ & $\begin{array}{c}.369 \\
\left(6.886^{* *}\right)\end{array}$ \\
\hline $\begin{array}{c}\text { payment } \\
\text { system }\end{array}$ & & & $\begin{array}{c}.239 \\
\left(5.802^{* *}\right) \\
\end{array}$ & $\begin{array}{c}.216 \\
\left(5.097^{* *}\right) \\
\end{array}$ \\
\hline \multicolumn{5}{|l|}{ cost } \\
\hline cost & & & & $\begin{array}{c}.088 \\
\left(2.269^{*}\right) \\
\end{array}$ \\
\hline Adj $R^{2}$ & .141 & .402 & .552 & .556 \\
\hline $\mathrm{F}$ & $10.051^{* *}$ & $31.347^{* *}$ & $44.817^{* *}$ & $42.532^{* *}$ \\
\hline
\end{tabular}

\section{V. 결론 및 함의}

본 연구 결과에서 사용자 인터페이스가 이용 만족도에 영향을 주는 가장 중요한 요인으로 도출된 것으로 볼 때, 고객 관계 관리(Customer Relationship Management) 기반 의 정량적인 이용행태 분석을 통해 사용자 맞춤형 콘텐츠 배치가 필요하다는 것을 알 수 있다. 다양한 연령대에서 $\mathrm{N}$ 스크린을 통한 콘텐츠 이용이 이뤄지고 있는 만큼 고객 세 분화를 통해 맞춤형 서비스를 제공하여 보다 최적화된 콘 텐츠 이용환경을 제공해야 할 것이다. 결제 시스템의 경우 에도 어떤 디바이스에서도 이용자가 쉽고 편리하게 비용을 지불할 수 있도록 발전되어야 한다. 특히 표준 웹 기반에서 콘텐츠 서비스와 결제시스템이 원활하게 동작한다면 $\mathrm{N}$ 스 크린 서비스와 사용자 인터페이스가 보다 개선될 수 있을 것이다. 향후 $\mathrm{N}$ 스크린 이용자들은 다양하고 쉬운 이용방 식을 더욱 선호하게 되고, 이용이 증가하면서 서비스에 대 한 요구도 한층 더 커질 것이다. 현재의 스마트TV는 단말 의 특성상 $\mathrm{N}$ 스크린 정액권과 상관없이 추가 결제를 해야 하고 콘텐츠 제공 범위에도 차이가 있어 이용이 확대되지 못하고 있는데, 향후 고정 TV에 인터넷이 연결되어 스마트 TV가 활성화되기 위해서는 이용자 인터페이스를 개선하여 사용 용이성을 제고해야 할 것이다. 현재 $\mathrm{N}$ 스크린 서비스 이용자들은 자신이 보유한 단말에서 서비스를 자유롭고 편

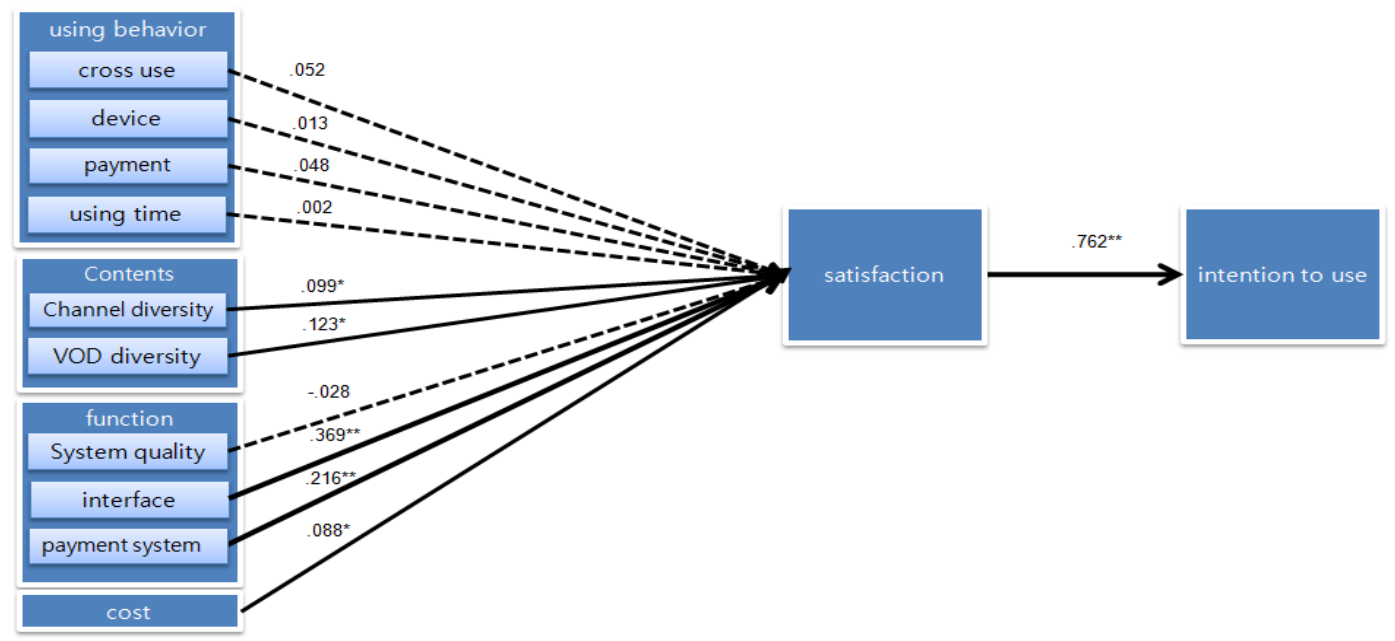

그림 2. 연구결과

Fig. 2 Research result 
리하게 이용하고 있는데, 특히 모바일 단말의 경우, 사용하 는 OS 플랫폼 별로 어플리케이션 내 상품이용가격, 결제가 능 여부, 단말별 해상도 지원 등에 대해 지속적으로 서비스 품질관리를 함으로써 이용만족도를 한층 제고해야 할 것이 다.

더불어, 콘텐츠 요인이 이용만족도에 모두 유의한 영향 을 미치는 것으로 보아 사업자는 콘텐츠에 대한 다양성을 증진시킬 필요가 있다. 즉 전통적으로 경쟁력이 강한 지상 파 콘텐츠 뿐만 아니라 20-30대의 선호도가 높은 케이블 초방 콘텐츠, 그리고 해외 시리즈, 최신 개봉 영화 등 이용 자 선호도가 높은 콘텐츠를 수급할 필요가 있는데, 이를 위 해 $\mathrm{N}$ 스크린 플랫폼 사업자는 콘텐츠 보유 사업자와 긴밀 한 서비스 제휴가 필요하다고 할 수 있다.

한편 이용 행태 가운데 단말기 보유량이나 지불금액, 이 용 시간은 유의미하지 않고, 교차이용만 모델 3까지 유의한 결과로 도출된 것은 스마트 미디어 이용자에게는 교차이용 이 보편화되고 있음을 짐작할 수 있다. 이를 통해 향후 복수 디바이스를 통해 서비스를 이어서 보는 것 이외에 텍스트 와 관련된 소셜 미디어 이용이 증가할 가능성이 많음을 알 수 있다. 향후 $\mathrm{N}$ 스크린 서비스는 멀티 디바이스의 보급과 더불어 이용방식이 더욱 다양화될 것이다.

반면, 시스템 품질이 서비스 만족도에 유의미한 변인으 로 나타나지 않은 것은 모바일 네트워크 속도가 고도화되 면서 이용자들이 네트워크 품질의 차이를 크게 인지하지 못하는 결과로 추정된다. 스마트폰과 태블릿 단말의 사양 이 급격하게 좋아진 점도 시스템 품질 간 차이가 나타나지 않는 원인으로 작동한 것으로 보인다. 향후 $\mathrm{N}$ 스크린 서비 스가 초고화질 영상의 제공가능성이 높은 만큼 네트워크 품질에 대한 지속적인 강화도 필요하다고 볼 수 있다.

본 연구는 $\mathrm{N}$ 스크린 서비스를 이용자 차원에서 서비스 만족에 영향을 주는 요인들을 밝혀냄으로써, $\mathrm{N}$ 스크린을 비롯한 OTT(Over The Top)의 이용을 예측하고 스마트TV 와 관련된 정책 입안에도 도움을 줄 수 있는 기초 자료를 제공할 것으로 기대한다.

\section{참 고 문 헌}

[1] Gyeong-su Oh, Determinants of Intention to Use toward N Screen Service for Potential User, Journal of the Korea Contents Association, Vol 12, No 9, 80-92. 2012.

[2] Hyeong-geun Baek et al, Determinants of Intention to Use N-Screen Service among College Students, Korean Journal of Broadcasting and Telecommunication Studies, Vol 27, No 1, 94-130, 2013.

[3] EBS, A Study of EBS multi-screen services, content distribution, and system preparation, EBS Research Report. 2012.

[4] Myung-ja Yang, Investigating the Factors Affecting Smart Phone Users' Intention to Pay for N-screen Services, Korean Journal of Broadcasting and Telecommunication Studies, Vol 27, No 1, 131-166, 2013.

[5] Yun Han et al, Relationship between N-screen Service and Home TV: Focusing on the Korean Representative N-Screen Service, Tving, Journal of the Korea Contents Association, Vol 12, No 5, 144-153, 2011.

[6] Ju-seong Hwang, Connected-device Use in the Multi-device Environment, Journal of Cybercommunication Academic Society, 131-171, 2012.

[7] Su-hyeon Kim, Effects of Functional Attributes of IPTV Service on the Purchase Intention, Journal of the Korea Contents Association, Vol 9, No 22, 261-269, 2008 .

[8] Cheol-ho Jeong, Effects of Contents Quality on User"s Satisfaction and Continuous Usage Intention in UCC Services, Journal of the Korea Contents Association, Vol 9, No 7, 294-303, 2009.

[9] Zoller, E. \& Doran, J. New dynamics in mobile TV and video: The emerging service landscape and competitive environment. OVUM. 2011.

[10] Jong-yun Lee, A Study on Acceptance Factors of Smart TV, Korean Journal of Broadcasting and Telecommunication Studies, Vol 26, No 4, 386-430, 2012.

[11] Seock-il Ryu, Mobile Phone Problems and Solutions related to retail payment, Korea Consumer Agency report, 1-50, 2011.

[12] Mi-seon Sim, Exploring the Studies on the Multiple-media Using Patterns : Focusing on the Concept of Media Repertoires, Journal of Communication Research, Vol 47, No 2, 40-73, 2010.

[13 Young-geun Back, The Research on Effect of IPTV's properties on Reception Satisfaction and Continuous Use, Journal of Korea Internet e-Commerce Association, Vol 10, No 2, 191-205, 2010.

[14] Bhattacherjee, A., Understanding Information Systems Continuance : An Expectation -Confirmation Model. Mis Quarterly, Vol 25, No 3, PP351-370. 2001.

[15] So-hye Im, N Screen Service Users' Motivations for Use and Dissatisfying Factors, Journal of the Korea Contents Association, Vol 13, No 3, 99-108, 2013.

[16] Won-tae Lee et al, N-Screen Content Usage Experience and Future Policy Issues, KISDI Research Report. 


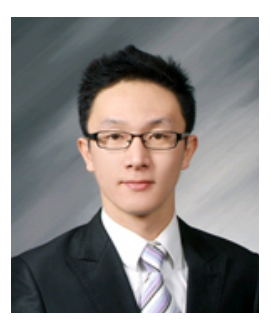

\section{김 동 우}

- 2011년 : 서울과학기술대학교 전지정보공학(학사)

- 2013년 : 서울과학기술대학교 IT정책대학원 방송통신정책(석사)

- 현재 : 한국디지털미디어산업협회 정책협력부 근무

- 주관심분야 : 미디어 이용행태, 방송통신정책, 디지털방송

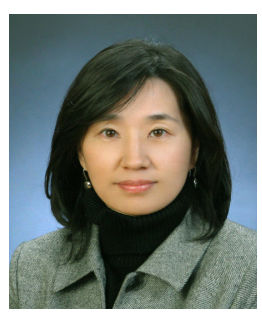

\section{이 영 주}

- 1992년 2월 : 이화여대 영어영문학(학사)

- 1998년 8월 : 서강대 신문방송학(석사)

- 2005년 8월 : 이화여대 언론홍보영상학(박사)

- 2007년 3월 2009년 2월 : 호남대학교 신문방송학과 교수

- 2009년 3월 현재 : 서울과학기술대학교 IT정책대학원 교수

- 주관심분야 : ICT 산업, IT정책, 미디어콘텐츠 